
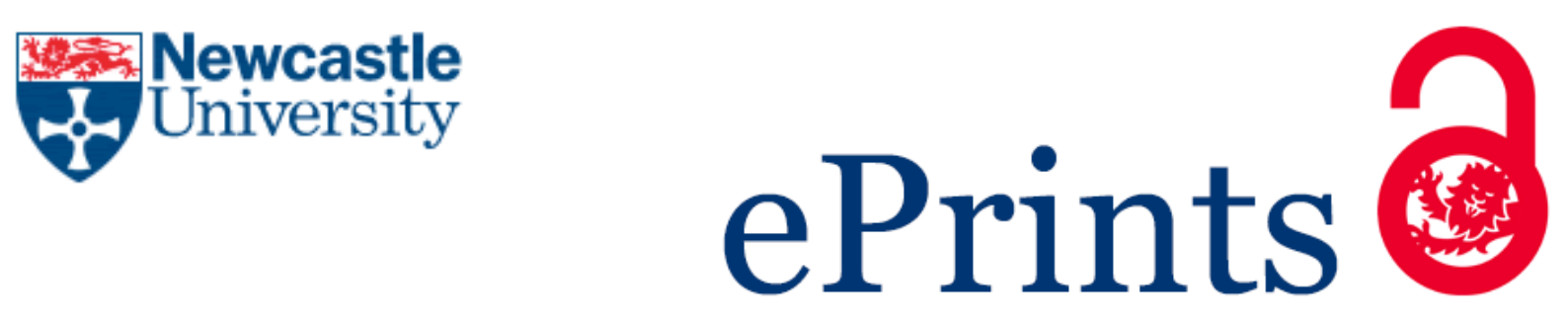

\author{
Papaioannou EI, Bachmann C, Neumeier JJ, Frankel D, Over H, Janek J, \\ Metcalfe IS.
}

The role of the three-phase boundary of the platinum-support interface in catalysis: A model catalyst kinetic study.

ACS Catalysis 2016, 6, 5865-5872.

\title{
Copyright:
}

This is an open access article published under a Creative Commons Attribution (CC-BY) License, which permits unrestricted use, distribution and reproduction in any medium, provided the author and source are cited.

DOI link to article:

http://dx.doi.org/10.1021/acscatal.6b00829

Date deposited:

$22 / 07 / 2016$

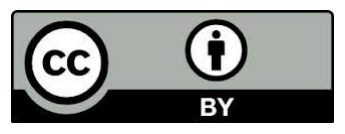

This work is licensed under a Creative Commons Attribution 4.0 International License 


\section{Role of the Three-Phase Boundary of the Platinum-Support Interface in Catalysis: A Model Catalyst Kinetic Study}

Evangelos I. Papaioannou, ${ }^{\dagger,}$ Christoph Bachmann, ${ }^{\ddagger}, \S$ Jonas J. Neumeier, ${ }^{\ddagger}$ Daniel Frankel, ${ }^{\dagger}$ Herbert Over, ${ }^{\sharp}$ Juergen Janek, ${ }^{* *+}$ and Ian S. Metcalfe, ${ }^{*, \dagger}$

${ }^{\dagger}$ School of Chemical Engineering and Advanced Materials, Newcastle University, Merz Court, Newcastle-upon-Tyne NE1 7RU, U.K.

${ }^{\ddagger}$ Institute for Physical Chemistry, Justus-Liebig-University of Giessen, Heinrich-Buff-Ring 17, 35392 Giessen, Germany

\section{Supporting Information}

ABSTRACT: A series of microstructured, supported platinum (Pt) catalyst films (supported on single-crystal yttria-stabilized zirconia) and an appropriate $\mathrm{Pt}$ catalyst reference system (supported on single-crystal alumina) were fabricated using pulsed laser deposition and ion-beam etching. The thin films exhibit areaspecific lengths of the three-phase boundary (length of three-phase boundary between the $\mathrm{Pt}$, support, and gas phase divided by the superficial area of the sample) that vary over 4 orders of magnitude from $4.5 \times 10^{2}$ to $4.9 \times 10^{6} \mathrm{~m} \mathrm{~m}^{-2}$, equivalent to structural length scales of $0.2 \mu \mathrm{m}$ to approximately $9000 \mu \mathrm{m}$. The

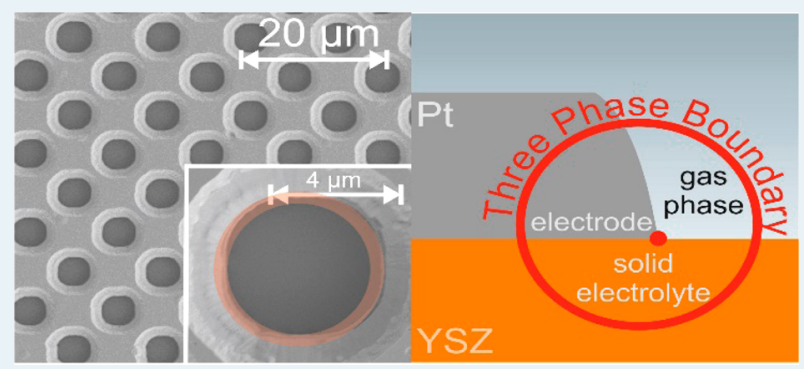
catalyst films have been characterized using X-ray diffraction, atomic force microscopy, high-resolution scanning electron microscopy, and catalytic activity tests employing the carbon monoxide oxidation reaction. When Pt is supported on yttriastabilized zirconia, the reaction rate clearly depends upon the area-specific length of the three-phase boundary, $l(\mathrm{tpb})$. A similar relationship is not observed when Pt is supported on alumina. We suggest that the presence of the three-phase boundary provides an extra channel of oxygen supply to the Pt through diffusion in or on the yttria-stabilized zirconia support coupled with surface diffusion across the Pt.

KEYWORDS: model catalysts, patterned catalysts, three-phase boundary, carbon monoxide kinetics

\section{INTRODUCTION}

In heterogeneous catalysis the reaction mixture comes into contact with the surface of a catalyst, which often consists of supported particles of the active component dispersed and immobilized on a high-surface-area carrier. These carriers are often oxides such as magnesia $(\mathrm{MgO})$, silica $\left(\mathrm{SiO}_{2}\right)$, and alumina $\left(\mathrm{Al}_{2} \mathrm{O}_{3}\right)$. The active particles themselves may exhibit various facets as well as defects such as edges and kinks, which may have different catalytic roles. It is known that the interaction of the active component with the support may have a profound effect on the activity and selectivity of a catalyst. $^{1 \mathrm{a}-\mathrm{c}}$ A relationship between catalytic activity and the presence of an oxide-metal interface was first suggested by Schwab. ${ }^{2}$ Seminal work has, for instance, shown that the role of an oxide support can be used to explain the unusual catalytic behavior of gold nanoparticles deposited on supports such as $\mathrm{TiO}_{2}$ and $\mathrm{CeO}_{2} \cdot{ }^{3 \mathrm{a}-\mathrm{c}} \mathrm{A}$ number of theoretical models have been proposed to describe the effect of an oxide support on the catalytic activity of metallic catalysts. ${ }^{4}$ In general, the oxide support can interact with the active phase through geometrical effects (e.g., strain due to presence of support), electronic effects (e.g., charge transfer between the metal and the oxide support), ${ }^{5,6}$ or the creation of special interfacial sites (where sites at the metal-support interface are responsible for high activity), ${ }^{5 a, 7}$ or even as a source or sink of intermediate species that may diffuse over the catalyst. ${ }^{5 b, 8}$ The surface diffusion of intermediate species, promoters, etc. can affect sites even micrometers away from the interface. ${ }^{8 b}$ Therefore, from a structural point of view heterogeneous catalysts represent a rather complex situation.

In order to gain atomic scale insights into a heterogeneously catalyzed reaction system, one has to resort to model catalysts. The chosen model system must be carefully designed to adequately probe the relevant aspects of the real reaction system. ${ }^{10}$ One should also take into account that real reaction systems are typically operated at elevated pressures equal to or greater than atmospheric pressure and can be chemically different from model systems under idealized experimental conditions. Most model metal catalysts are usually unsupported single crystals, and kinetic experiments are usually performed at pressures much lower than atmospheric. So far there have been very few reports on Pt-based supported model catalyst systems with kinetics investigated at atmospheric pressure. Contreras et al. ${ }^{11}$ demonstrated the importance of the nature of the support using a series of arrays of $\mathrm{Pt}$ nanowires supported on oxide films as model catalyst systems. Strong support dependence

Received: March 22, 2016

Revised: July 18, 2016

Published: July 22, 2016 


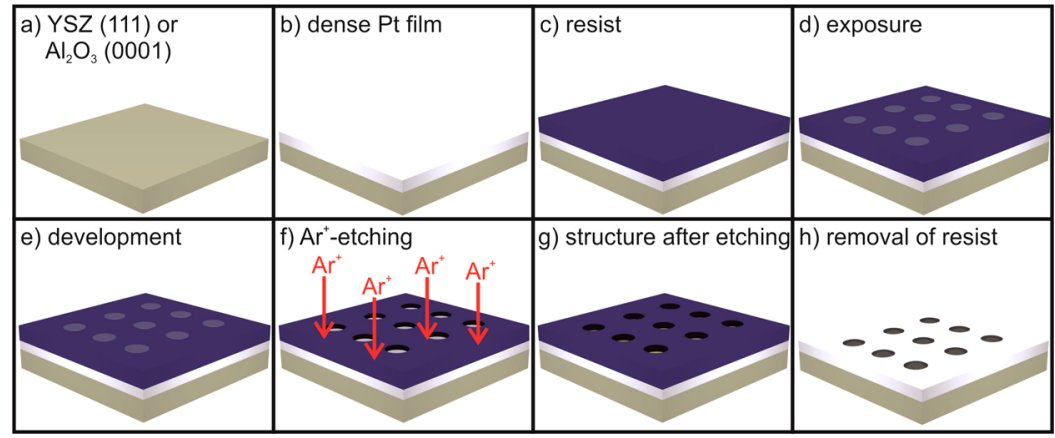

Figure 1. Different steps for structuring the YSZ- and $\mathrm{Al}_{2} \mathrm{O}_{3}$-supported $\mathrm{Pt}$ films by a subtractive lithographic technique. See text for description.

was also reported for both reaction turnover frequency and the activation energy for the $\mathrm{CO}$ oxidation reaction. Nevertheless, the structural complexity of the model system used (i.e., polycrystalline $\mathrm{Pt}$ and polycrystalline supports) and the fact that the catalysts used were subject to structural changes during operation makes interpretation of the results somewhat difficult. ${ }^{11}$ Johansson et al. ${ }^{12}$ compared the activity of $750 \mathrm{~nm}$ diameter Pt features supported upon both ceria $\left(\mathrm{CeO}_{2}\right)$ and silica $\left(\mathrm{SiO}_{2}\right)(200 \mathrm{~nm}$ diameter features were also used for $\mathrm{Pt}$ on $\mathrm{CeO}_{2}$ for comparison). There was a clear difference in activity between the $\mathrm{CeO}_{2-}$ and $\mathrm{SiO}_{2}$-supported $\mathrm{Pt}$ systems. This finding was explained by the appearance of "an extra channel of oxygen supply" for $\mathrm{Pt}$ in the case of a $\mathrm{CeO}_{2}$ support through oxygen surface diffusion from $\mathrm{CeO}_{2}$ to the Pt. However, the range of three-phase boundary (tpb) lengths available for experiment was limited.

In an attempt to further reduce the structural complexity of a combination of $\mathrm{Pt}$ catalyst with an oxygen-delivering (ionconducting) support, we employ single-crystal yttria-stabilized zirconia (YSZ, $8 \mathrm{~mol} \%$ ) and $\mathrm{Al}_{2} \mathrm{O}_{3}$ as support materials together with geometrically well defined Pt films. YSZ exhibits high oxygen ion conductivity but has poor electronic conductivity and is thus relatively stable against chemical reduction in the bulk..$^{13,14}$ Hence, we might expect YSZ to interact with the catalyst but without the complexity associated with many other reducible support materials, such as $\mathrm{CeO}_{2}$ and $\mathrm{TiO}_{2}{ }^{15,16}$ In the case of an $\mathrm{Al}_{2} \mathrm{O}_{3}$ support, we expect little contribution to the reaction from the $\mathrm{Al}_{2} \mathrm{O}_{3}$ surface (in the case of e.g. $\mathrm{CO}$ oxidation), and furthermore $\mathrm{Al}_{2} \mathrm{O}_{3}$ is not expected to modify the active Pt catalyst to any great extent. The strategy of our experimental approach is to investigate the role of the tpb between the support, the catalyst, and the gas phase by preparing and employing a series of Pt films with different geometries on otherwise identical substrates. Furthermore, in order to be able to extract reliable kinetic data, we work below the light-off temperature of the reaction. Hence, the design of the model catalyst system and apparatus for kinetic measurements should take into consideration heat and mass transfer effects so that light-off can be avoided.

Oriented Pt films of high quality, being structurally close to single-crystal films, can be prepared by pulsed laser deposition (PLD). ${ }^{17}$ We employed PLD to fabricate dense and welladhering $\mathrm{Pt}$ films on both YSZ and $\mathrm{Al}_{2} \mathrm{O}_{3}$ single-crystal surfaces: i.e. $\mathrm{Pt}(111) / \mathrm{YSZ}(111)$ and $\mathrm{Pt}(111) / \mathrm{Al}_{2} \mathrm{O}_{3}(0001)$ samples with $9 \mathrm{~mm} \times 9 \mathrm{~mm}$ area. These films, with full surface coverage, were then further treated by a subtractive lithographic technique. Partially dewetted Pt films were also produced by PLD to obtain additional samples with different $l(\mathrm{tpb})$ values but without employing lithography. Using both approaches, we were able to obtain structural length scales of $\mathrm{Pt}$ between $0.2 \mu \mathrm{m}$ and approximately $9000 \mu \mathrm{m}$ corresponding to total lengths of the tpb of between $4.5 \times 10^{2}$ and $4.9 \times 10^{6} \mathrm{~m}$ $\mathrm{m}^{-2}$, respectively. The influence of the length and the nature of the tpb on the catalytic properties of the patterned $\mathrm{Pt}(111)$ single-crystal catalysts for $\mathrm{CO}$ oxidation was then studied as a function of temperature and partial pressures of $\mathrm{O}_{2}\left(p\left(\mathrm{O}_{2}\right)\right)$ and $\mathrm{CO}(p(\mathrm{CO}))$ at atmospheric pressure.

\section{EXPERIMENTAL SECTION}

Sample Preparation and Characterization. Pt catalysts on solid electrolyte $\mathrm{YSZ}$ and $\mathrm{Al}_{2} \mathrm{O}_{3}$ were produced following the route described by Beck et al. ${ }^{17}$ In a first step the Pt films were deposited by PLD on YSZ (111) single crystals (CrysTec, disks with a diameter of $20 \mathrm{~mm}$ ) and $\mathrm{Al}_{2} \mathrm{O}_{3}$ (0001) single crystals (CrysTec, squares with an edge length of $10 \mathrm{~mm}$ ) using a $\operatorname{KrF}(\lambda 248 \mathrm{~nm}$, ComPex LAMBDA Physik Lasertechnik) excimer laser with a pulse energy of $300 \mathrm{~mJ}$ (Figure 1a,b). Argon was used as background gas with a gas pressure of $1 \mathrm{~Pa}$. A commercial Pt target (99.95\% Degussa) was placed at a distance of $45 \mathrm{~mm}$ from the substrate. The deposition time, repetition rate, and substrate temperature controlled the morphology of the Pt catalysts. The deposition time was 100 min with a repetition rate of $10 \mathrm{~Hz}$ at a substrate temperature of $700{ }^{\circ} \mathrm{C}$. In order to obtain a well-defined geometric surface area of $9 \mathrm{~mm} \times 9 \mathrm{~mm}$, a Pt-coated stainless steel mask was placed on the substrate prior to deposition. The thickness of the Pt films was approximately $1 \mu \mathrm{m}$, as measured by profilometry. To stabilize the morphology and to smoothen the surface of the Pt films, the samples were heated in air, increasing the temperature from room temperature to $750{ }^{\circ} \mathrm{C}$ at a heating rate of $1.7^{\circ} \mathrm{C} \mathrm{min}{ }^{-1}$, and then holding the sample at $750{ }^{\circ} \mathrm{C}$ for $180 \mathrm{~min}$.

For patterning, the dense Pt films were further treated by a subtractive lithographic technique which consists of the following different steps. A photoresist was deposited on the dense catalyst films by spin coating, which was followed by a heat treatment (soft bake, $100{ }^{\circ} \mathrm{C}$ for $120 \mathrm{~s}$ ) to increase the stability of the photoresist (Figure 1c). A chromium-coated photo mask with the desired transferable structure was aligned on the sample; the photoresist was exposed for $88 \mathrm{~s}$ (Figure 1d) and developed afterward for $60 \mathrm{~s}$ (Figure 1e). The resulting resist pattern, which was identical with the photo mask pattern, was transferred to the underlying $\mathrm{Pt}$ layer by an ion beam etching process $\left(\mathrm{Ar}^{+}\right.$ions, Figure 1f,g). (The etch rate employed was determined from test samples, for which energy-dispersive $\mathrm{X}$-ray (EDX) spectroscopy was used to confirm the removal of the $\mathrm{Pt}$ layer in the etched areas; results 
are not shown here.) The final treatment was resist stripping by an organic solvent for $120 \mathrm{~min}$ (Figure $1 \mathrm{~h}$ ).

High-resolution scanning electron microscopy (HRSEM) micrographs were taken after the ablation process and after the resist removal stage. After the ablation and sintering stage the Pt film showed a smooth and dense surface, but the edges of the film had frayed irregular contours (Figure S1a in the Supporting Information). Nevertheless, after the removal of the resist the Pt edges presented a sharp structure, although the $\mathrm{Pt}$ surface had been roughened due to the etching and removal processes (Figure S1b,c).

Patterns were made using holes of diameter $4.9 \pm 0.05 \mu \mathrm{m}$ in a square arrangement. Furthermore, one $\mathrm{Al}_{2} \mathrm{O}_{3}$-supported "patterned" sample was prepared in exactly the same way but with no holes being formed. The numbers of holes used in the pattern formation were $50 \times 10^{3}, 200 \times 10^{3}$, and $800 \times 10^{3}$ in the case of the YSZ-supported Pt film. This corresponds to hole densities of $6.2 \times 10^{8}, 2.5 \times 10^{9}$, and $9.9 \times 10^{9} \mathrm{~m}^{-2}$. The approximate Pt structural length scale of the sample was simply estimated from the center-to-center separation of nearestneighbor holes. This results in structural length scales of 33, 18, and $9 \mu \mathrm{m}$, and these samples are referred to as 1PtYSZ, $4 \mathrm{PtYSZ}$, and $16 \mathrm{PtYSZ}$, respectively. The Pt tpb length can be estimated from the number of holes. (It should be noted that the tpb length we refer to here is the macroscopically observable tpb. The macroscopically observable tpb is not necessarily the same as the microscopic tpb; Ryll et al. ${ }^{18}$ have shown the importance of grain boundaries, grooves, and voids in an electrode in the electrical polarization of a $\mathrm{Pt} / \mathrm{YSZ}$ system.) The total length of tpb and specific length of tpb for these samples were 1,4 , and $16.2 \mathrm{~m}$ and $1.2 \times 10^{4}, 4.9 \times 10^{4}$, and $2 \times 10^{5} \mathrm{~m} \mathrm{~m}^{-2}$, respectively. Figure $2 \mathrm{a}-\mathrm{c}$ shows HRSEMs of 1PtYSZ, 4PtYSZ, and 16PtYSZ, respectively.

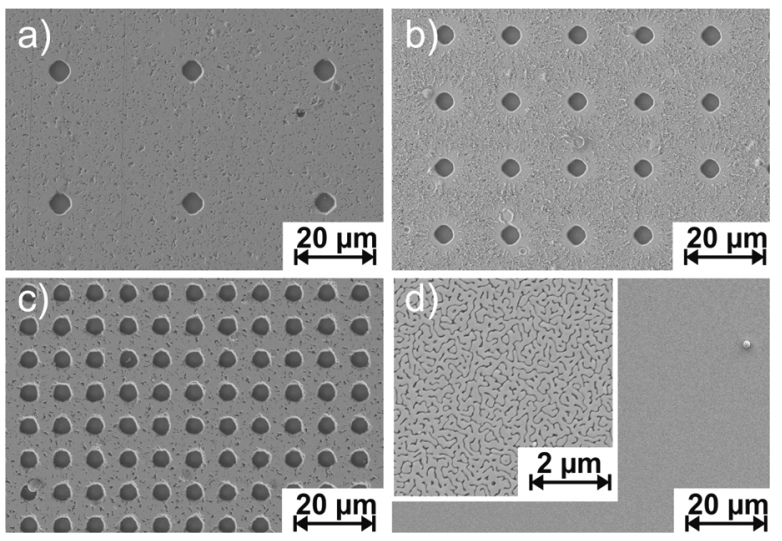

Figure 2. HRSEM images of samples: (a) 1PtYSZ; (b) 4PtYSZ; (c) 16PtYSZ; (d) 400PtYSZ.

The number of holes used in the pattern formation were 50 $\times 10^{3}$ in the case of the $\mathrm{Al}_{2} \mathrm{O}_{3}$-supported $\mathrm{Pt}$ film. This corresponds to a hole density of $6.2 \times 10^{8} \mathrm{~m}^{-2}$. This results in a Pt structural length scale of $33 \mu \mathrm{m}$. An additional $\mathrm{Al}_{2} \mathrm{O}_{3}$ supported sample was prepared with no holes in the pattern. The Pt structural length scale for this sample is approximated by the length of one edge of the feature or $9000 \mu \mathrm{m}$. These samples are referred to as $1 \mathrm{PtAl}_{2} \mathrm{O}_{3}$ and $0.04 \mathrm{PtAl}_{2} \mathrm{O}_{3}$, respectively. The total length of tpb and specific length of tpb for these samples were 1 and $3.6 \times 10^{-2} \mathrm{~m}$ and $1.2 \times 10^{4}$ and $4.5 \times 10^{2} \mathrm{~m} \mathrm{~m}^{-2}$, respectively.
Additionally, a second type of catalyst was prepared on YSZ and $\mathrm{Al}_{2} \mathrm{O}_{3}$ supports. By increasing the deposition temperature and decreasing the amount of pulses during the PLD process, partially dewetted Pt films with thicknesses between 50 and 130 nm were obtained. For detailed deposition conditions the reader is referred to ref 19 . In the case of dewetted samples the $\mathrm{Pt}$ tpb length was estimated using the software Adobe Photoshop (version CS4 extended). The Pt structural length scale is estimated by the ratio of surface area of the Pt film to tpb length. This results in a Pt structural length scale of $0.2 \mu \mathrm{m}$, and the samples are referred to as $400 \mathrm{PtYSZ}$ and $400 \mathrm{PtAl}_{2} \mathrm{O}_{3}$ for the YSZ-supported and the $\mathrm{Al}_{2} \mathrm{O}_{3}$-supported samples, respectively. The total length of tpb and specific length of tpb for these samples were $400 \mathrm{~m}$ and $4.9 \times 10^{6} \mathrm{~m} \mathrm{~m}^{-2}$, respectively. Figure $2 \mathrm{~d}$ shows an HRSEM of the 400PtYSZ sample.

Table 1 compiles the numbers of holes, the total lengths of $\mathrm{tpb}$, the $l(\mathrm{tpb})$ values, the $\mathrm{Pt}$ film thicknesses, and the $\mathrm{Pt}$ structural length scales for the samples used in this study.

Atomic force microscopy (AFM) was used to further characterize the surface of the Pt films as well as the walls and the base of the holes in the film. AFM experiments were conducted with an Agilent 5500 AFM microscope in air. Images were obtained in contact mode using nitrogen-doped silicon tips with a force constant of $0.02-0.77 \mathrm{~N} \mathrm{~m}^{-1}$. Typical scan rates were in the range of $0.5-1 \mathrm{kHz}$ and 512 by 512 pixel resolution. Image processing was performed using version 5.1.6 of the Scanning Probe Image Processor (SPIP) software (Image Metrology, Lyngby, Denmark). The AFM topographic image (Figure S2a in the Supporting Information) show a Pt wall exhibiting imperfections, unavoidable defects of the fabrication process. Of particular interest are nanoscale features on the base of the holes (Figure S2b), approximately $5 \mathrm{~nm}$ in height and tens of nanometers laterally. These features are most likely irregularities on the YSZ surface due to ion beam bombardment during the etching process.

All samples were characterized after the preparation process and before any experimental work by X-ray diffraction (XRD). All samples showed exclusively the (111) orientation, in line with previous reports. ${ }^{17}$ Figure S3 in the Supporting Information shows the XRD pattern for the sample 16PtYSZ. Similar XRD patterns were obtained for all YSZ- and $\mathrm{Al}_{2} \mathrm{O}_{3}$ supported samples. XRD shows narrow peaks (indicative of highly crystalline material) characteristic of Pt. A low-intensity peak and shoulder to the left of the $\operatorname{Pt}(111)$ reflection can be attributed to trace amounts of material with argon implanted into the $\mathrm{Pt}(111)$ plane. This is a common phenomenon associated with the sputtering process. ${ }^{20}$

It is possible that there could be contamination of the $\mathrm{Pt}$ surface in the region of the three-phase boundary as a result of the ablation process. Such contamination could be catalytically significant and is difficult to characterize, as what constitutes a catalytically significant level of contamination is unknown. However, one should recall that for both YSZ-supported and $\mathrm{Al}_{2} \mathrm{O}_{3}$-supported $\mathrm{Pt}$ films a second fabrication method employing dewetting was also applied. One might thus expect the level of contamination, if present, to be different in such samples. These different fabrication methods then allow comment to be passed on the likelihood of catalytically significant contamination occurring during fabrication.

It is worth mentioning that HRSEM micrographs and XRD data obtained after the experiments indicated no morphological 
Table 1. Pattern Characteristics and Pt Structural Length Scales

\begin{tabular}{|c|c|c|c|c|c|c|}
\hline sample & support & no. of holes $\left(\times 10^{3}\right)$ & tpb length $(\mathrm{m})$ & $l(\mathrm{tpb})\left(\mathrm{m} \mathrm{m}^{-2}\right)$ & Pt film thickness $(\mu \mathrm{m})$ & Pt structural length scale $(\mu \mathrm{m})$ \\
\hline 400PtYSZ & YSZ & & 400 & $4.9 \times 10^{6}$ & $0.05-0.13$ & $0.2^{b}$ \\
\hline $400 \mathrm{PtAl}_{2} \mathrm{O}_{3}$ & $\mathrm{Al}_{2} \mathrm{O}_{3}$ & & 400 & $4.9 \times 10^{6}$ & $0.05-0.13$ & $0.2^{b}$ \\
\hline 16PtYSZ & YSZ & 800 & 16.2 & $2 \times 10^{5}$ & 1 & $9^{a}$ \\
\hline 4PtYSZ & YSZ & 200 & 4 & $4.9 \times 10^{4}$ & 1 & $18^{a}$ \\
\hline 1PtYSZ & YSZ & 50 & 1 & $1.2 \times 10^{4}$ & 1 & $33^{a}$ \\
\hline $1 \mathrm{PtAl}_{2} \mathrm{O}_{3}$ & $\mathrm{Al}_{2} \mathrm{O}_{3}$ & 50 & 1 & $1.2 \times 10^{4}$ & 1 & $33^{a}$ \\
\hline $0.04 \mathrm{PtAl}_{2} \mathrm{O}_{3}$ & $\mathrm{Al}_{2} \mathrm{O}_{3}$ & 0 & $3.6 \times 10^{-2}$ & $4.5 \times 10^{2}$ & 1 & $9000^{c}$ \\
\hline
\end{tabular}

${ }^{a} \mathrm{Pt}$ structural length scale is estimated from the center-to-center separation of nearest-neighbor holes. ${ }^{b} \mathrm{Pt}$ structural length scale is estimated by the ratio of the surface area of the $\mathrm{Pt}$ film to tpb length. ${ }^{c} \mathrm{Pt}$ structural length scale is estimated by the length of one edge of the feature.

changes and no change in the crystalline structure of the Pt film supported on either $\mathrm{YSZ}$ or $\mathrm{Al}_{2} \mathrm{O}_{3}$.

Experimental Rig for Kinetic Evaluation. A continuousflow single-chamber reactor with a total gas-phase volume of 30 $\mathrm{cm}^{3}$ was used for the catalytic experiments. The flow of gas to the reactor was controlled by electronic mass flow controllers (MFCs). All experiments were conducted at atmospheric pressure. Flow rates are given at normal temperature and pressure (NTP). The sample temperature was measured by a K-type thermocouple placed in proximity to the $\mathrm{Pt}$ catalyst surface. The use of a planar catalyst sample as opposed to a porous catalyst should help avoid catalyst light-off, as the ratio of area for reaction to effective area for gas-solid heat transfer is close to unity (and relatively low). Furthermore, in order to ensure that there cannot be a significant difference between the sample temperature and the gas temperature as measured by the thermocouple, we limit the kinetic data employed in our analysis to rates of reaction below $4 \times 10^{-4} \mathrm{~mol} \mathrm{~s}^{-1} \mathrm{~m}^{2}$. (A value of $10 \mathrm{~W} \mathrm{~m}^{-2} \mathrm{~K}^{-1}$ for the heat transfer coefficient between the sample and the gas phase, a conservative value appropriate for natural convection or low gas velocities, ${ }^{21}$ with a heat of reaction of approximately $280 \mathrm{~kJ} \mathrm{~mol}^{-1}$ a rate of reaction of $4 \times$ $10^{-4} \mathrm{~mol} \mathrm{~s}^{-1} \mathrm{~m}^{-2}$ results in a maximum temperature difference between the sample and gas phase of $11 \mathrm{~K}$ ). The gases used were $20 \% \mathrm{CO} / \mathrm{He}, 20 \% \mathrm{O}_{2} / \mathrm{He}$, and $\mathrm{CP}$ grade $\mathrm{He}(\mathrm{N} 5)$ provided by BOC Ltd. with typical flow rates of $1 \times 10^{-4} \mathrm{~mol}$ $\mathrm{s}^{-1}\left(150 \mathrm{~cm}^{3} \mathrm{~min}^{-1}\right)$. The flow rates were also measured at the outlet using a Varian digital flow meter (1000 series). Helium was used as a balance gas throughout the experiments. The carbon dioxide $\left(\mathrm{CO}_{2}\right)$ concentration in the product stream was analyzed using a XTREAM- $\mathrm{CO}_{2}$ analyzer provided by Rosemount. The minimum detectable $\mathrm{CO}_{2}$ mole fraction for the XTREAM- $\mathrm{CO}_{2}$ analyzer was $1 \mathrm{ppm}$, which corresponds to a minimum measurable rate of $\mathrm{CO}_{2}$ production of $1 \times 10^{-10} \mathrm{~mol}$ $\mathrm{s}^{-1}$ with typical flow rate at $1 \times 10^{-4} \mathrm{~mol} \mathrm{~s}^{-1}\left(150 \mathrm{~cm}^{3} \mathrm{~min}^{-1}\right)$.

Reaction rates $\left(r_{\mathrm{CO}_{2}}\right)$ in terms of $\mathrm{CO}_{2}$ production are calculated as shown in eq 1 :

$$
r_{\mathrm{CO}_{2}}\left(\left(\mathrm{~mol} \text { of } \mathrm{CO}_{2}\right) \mathrm{s}^{-1} \mathrm{~m}^{-2}\right)=Y_{\mathrm{CO}_{2}} \dot{n} A^{-1}
$$

where $\mathrm{Y}_{\mathrm{CO}_{2}}$ is the measured $\mathrm{CO}_{2}$ mole fraction at the gas outlet, $\dot{n}$ is the molar flow, and $A$ is the total Pt area. In order to be able to measure the rate of $\mathrm{CO}_{2}$ production under "gradientless" conditions, the reactor was operated under conditions of differential conversion ( $5 \%$ conversion of $\mathrm{CO}$ or less).

In this study we use the term "superficial" area to describe the area of the external facets of the dense Pt single-crystal films and the term "pore" wall area to define the area of the vertical walls inside the holes. The total Pt area is the sum of the superficial area and the pore wall area. Table 2 shows the superficial area, the "pore" wall area, the total $\mathrm{Pt}$ area, and the moles of Pt corresponding to the total area for the samples used in this study.

Table 2. Characteristic Pt Surfaces and Moles of Pt Surface Atoms Used for the Calculation of Normalized Rates and TOFs

\begin{tabular}{lcccc}
\multicolumn{1}{c}{ sample } & $\begin{array}{c}\text { superficial } \\
\text { Pt area } \\
\left(\times 10^{-5} \mathrm{~m}^{2}\right)\end{array}$ & $\begin{array}{c}\text { pore wall Pt } \\
\text { area } \\
\left(\times 10^{-5} \mathrm{~m}^{2}\right)\end{array}$ & $\begin{array}{c}\text { amt of Pt } \\
\text { total Pt area } \\
\left(\times 10^{-5} \mathrm{~m}^{2}\right)\end{array}$ & $\begin{array}{c}\text { surface atoms } \\
\left(\times 10^{-10} \mathrm{~mol}^{a}\right)\end{array}$ \\
$400 \mathrm{PtYSZ}$ & $5.76^{b}$ & & & $12.3^{b}$ \\
$400 \mathrm{PtAl}_{2} \mathrm{O}_{3}$ & $5.76^{b}$ & & & $12.3^{b}$ \\
$16 \mathrm{PtYSZ}$ & 6.60 & 1.22 & 7.82 & 16.7 \\
$4 \mathrm{PtYSZ}$ & 7.79 & 0.303 & 8.09 & 17.2 \\
$1 \mathrm{PtYSZ}$ & 8.00 & 0.076 & 8.07 & 17.2 \\
$1 \mathrm{PtAl}_{2} \mathrm{O}_{3}$ & 8.00 & 0.076 & 8.07 & 17.2 \\
$0.04 \mathrm{PtAl}_{2} \mathrm{O}_{3}$ & 8.10 & 0 & 8.10 & 17.3
\end{tabular}

${ }^{a}$ Based on the total area. ${ }^{b}$ The area was calculated approximately from HRSEM micrographs via Photoshop software. The TOF calculation is based on this area.

The kinetic behavior of the samples during $\mathrm{CO}$ oxidation was first evaluated as a function of temperature. To study the effect of temperature, the samples were heated in a gas mixture of 1.3 $\mathrm{kPa}$ of $\mathrm{O}_{2}$ and $0.5 \mathrm{kPa}$ of $\mathrm{CO}$ from $150{ }^{\circ} \mathrm{C}$ up to $350{ }^{\circ} \mathrm{C}$. The temperature was held during heating after each step of $20^{\circ} \mathrm{C}$, the holding time being varied between 60 and $180 \mathrm{~min}$ depending on the time the reaction rate needed to become steady: i.e., the rate of $\mathrm{CO}_{2}$ production did not vary by more than $\pm 5 \%$ over $60 \mathrm{~min}$. The heating rate between the isothermal periods was $10{ }^{\circ} \mathrm{C} \mathrm{min}{ }^{-1}$.

Second, the rate of $\mathrm{CO}_{2}$ production dependence on $p(\mathrm{CO})$ and $p\left(\mathrm{O}_{2}\right)$ was also examined. In these experiments $p(\mathrm{CO})$ was held constant and $p\left(\mathrm{O}_{2}\right)$ was allowed to vary $\left(\mathrm{O}_{2}\right.$ dependence $)$ or vice versa ( $\mathrm{CO}$ dependence) at $288{ }^{\circ} \mathrm{C}$. To study the influence of oxygen $p(\mathrm{CO})=0.5 \mathrm{kPa}$ was held constant and $p\left(\mathrm{O}_{2}\right)$ was varied stepwise between 1.2 and $13.5 \mathrm{kPa}$ for the samples $1 \mathrm{PtYSZ}, 4 \mathrm{PtYSZ}, 16 \mathrm{PtYSZ}, 1 \mathrm{PtAl}_{2} \mathrm{O}_{3}$, and $400 \mathrm{PtAl}_{2} \mathrm{O}_{3}$ and between 0.05 and $13.5 \mathrm{kPa}$ for the sample 400PtYSZ with a varying step size of $0.05 \mathrm{kPa}$ up to $4 \mathrm{kPa}$. In a second series of experiments $p\left(\mathrm{O}_{2}\right)$ was held constant $(0.64 \mathrm{kPa})$ and $p(\mathrm{CO})$ was varied stepwise between 0.5 and $15 \mathrm{kPa}$ with a varying step size of $0.6 \mathrm{kPa}$ up to $2.8 \mathrm{kPa}$.

\section{RESULTS AND DISCUSSION}

Figure 3 shows the rate of $\mathrm{CO}_{2}$ production $\left(r_{\mathrm{CO}_{2}}\right)$ as a function of temperature over two different $\mathrm{Pt} / \mathrm{Al}_{2} \mathrm{O}_{3}$ samples, $0.04 \mathrm{PtAl}_{2} \mathrm{O}_{3}$ and $1 \mathrm{PtAl}_{2} \mathrm{O}_{3}$. The ratios of the "pore" wall $\mathrm{Pt}$ 


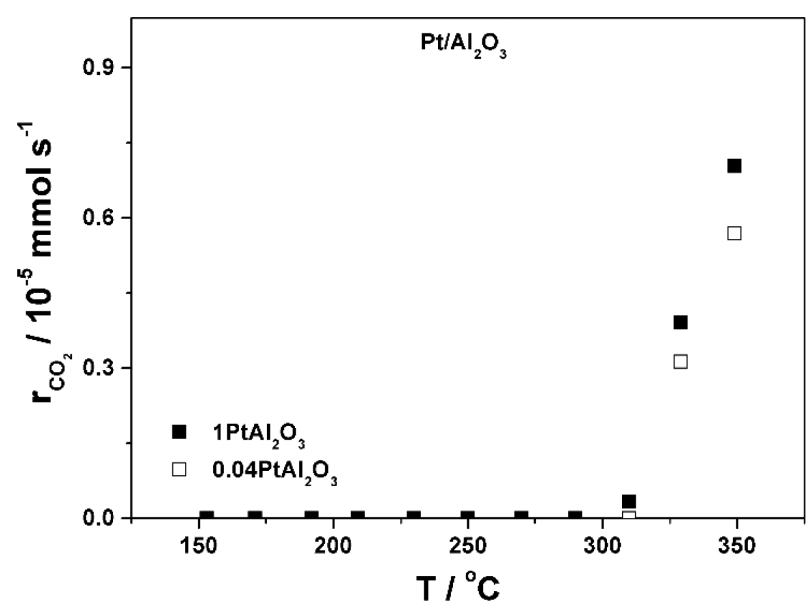

Figure 3. Effect of temperature on rate of $\mathrm{CO}_{2}$ production $\left(r_{\mathrm{CO}_{2}}\right)$ over two $\mathrm{Pt} / \mathrm{Al}_{2} \mathrm{O}_{3}$ samples $\left(0.04 \mathrm{PtAl}_{2} \mathrm{O}_{3}\right.$ and $\left.1 \mathrm{PtAl}_{2} \mathrm{O}_{3}\right)$ in a feed gas mixture of $p\left(\mathrm{O}_{2}\right)=1.3 \mathrm{kPa}$ and $p(\mathrm{CO})=0.5 \mathrm{kPa}$. Total gas flow rate: $1 \times 10^{-4} \mathrm{~mol} \mathrm{~s}^{-1}\left(150 \mathrm{~cm}^{3} \mathrm{~min}^{-1}\right)$.

area to the total $\mathrm{Pt}$ area for the two samples are different. For the sample $0.04 \mathrm{PtAl}_{2} \mathrm{O}_{3}$ this ratio is 0 , i.e. there is no "pore" wall sites, while for the sample $1 \mathrm{PtAl}_{2} \mathrm{O}_{3}$ this ratio equals $9.4 \times$ $10^{-3}$. It can be seen that the minimum temperature for a measurable rate of $\mathrm{CO}_{2}$ production was around $310{ }^{\circ} \mathrm{C}$ for both samples. Below $300{ }^{\circ} \mathrm{C}$ the rate of $\mathrm{CO}_{2}$ production was below the minimum measurable limit $\left(1 \times 10^{-10} \mathrm{~mol} \mathrm{~s}^{-1}\right)$. The activity of $\mathrm{Al}_{2} \mathrm{O}_{3}$-supported samples appears not to depend strongly on the number of sites in the "pore" wall available, and we tentatively conclude that these "pore" wall sites are not different from the $\mathrm{Pt}$ (111) sites of the superficial area in kinetic terms (at least in the presence of an inactive support). This is consistent with the structure-insensitive nature of $\mathrm{CO}$ oxidation over $\mathrm{Pt} / \mathrm{Al}_{2} \mathrm{O}_{3}{ }^{22}$ below the ignition regime. Henceforth we normalize the rates of $\mathrm{CO}_{2}$ production on a surface area basis assuming "pore" wall sites and superficial Pt (111) sites to be catalytically equivalent. The total $\mathrm{Pt}$ area is thus used in the normalization of the production rates of $\mathrm{CO}_{2}\left(r_{\mathrm{CO}_{2}}\right)$ (eq 1$)$. The rates of reaction $\left(\mathrm{CO}_{2}\right.$ production $)$ are also expressed in terms of turnover frequency (TOF), which is defined as the number of $\mathrm{CO}_{2}$ molecules produced per active site per second. Since the number of active sites is not strictly known, we estimate the total number of $\mathrm{Pt}$ surface atoms, $z$, and assume that there is one active site per surface $\mathrm{Pt}$ atom. Accordingly

$$
\operatorname{TOF}\left(\mathrm{s}^{-1}\right)=Y_{\mathrm{CO}_{2}} \dot{n} N_{\mathrm{A}} z^{-1}
$$

where $N_{\mathrm{A}}$ is Avogadro's constant. The product $N_{\mathrm{A}} z^{-1}$ is the number of moles of $\mathrm{Pt}$ surface atoms. The minimum measurable TOF value in our setup was $6 \times 10^{-2} \mathrm{~s}^{-1}$. We note that the dominant structural feature which differentiates the samples is the three-phase boundary length.

Figure 4 shows the natural logarithm of the TOF $(\ln (\mathrm{TOF} /$ $\mathrm{Hz})$ ) versus the inverse temperature (Arrhenius plot) for reaction over the four $\mathrm{Pt} / \mathrm{YSZ}$ samples and two $\mathrm{Pt} / \mathrm{Al}_{2} \mathrm{O}_{3}$ samples (samples $1 \mathrm{PtAl}_{2} \mathrm{O}_{3}$ and $400 \mathrm{PtAl}_{2} \mathrm{O}_{3}$ ) and over the $\mathrm{Pt}$ / zirconia $\left(\mathrm{Pt} / \mathrm{ZrO}_{2}\right)$ and $\mathrm{Pt} / \mathrm{Al}_{2} \mathrm{O}_{3}$ samples used by Contreras et al. ${ }^{11}$ (it was not possible to extract rate data from the work of Ryll et al.). ${ }^{20}$ In the Arrhenius plot we mark the limit where the maximum temperature difference between the sample and the gas phase is expected to be $11 \mathrm{~K}$. As Conteras et al. ${ }^{11}$ indicated, their data points lie in the regime above the light-off point

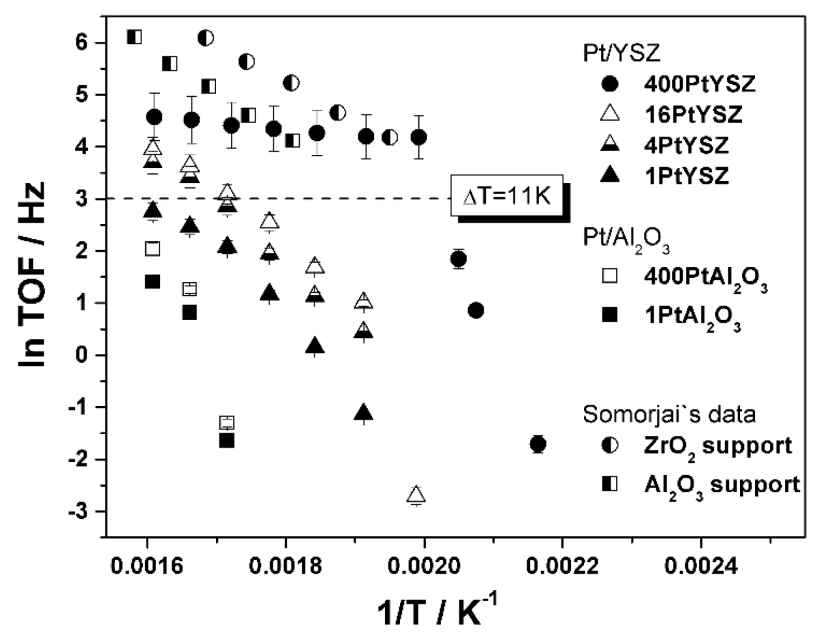

Figure 4. Natural logarithm of TOF values (ln TOF/Hz) versus the inverse temperature $(1 / \mathrm{K})$ for reaction over the four $\mathrm{Pt} / \mathrm{YSZ}$ samples and two $\mathrm{Pt} / \mathrm{Al}_{2} \mathrm{O}_{3}$ samples $\left(1 \mathrm{PtAl}_{2} \mathrm{O}_{3}\right.$ and $\left.400 \mathrm{PtAl}_{2} \mathrm{O}_{3}\right)$ in a feed gas mixture of $p\left(\mathrm{O}_{2}\right)=1.3 \mathrm{kPa}$ and $p(\mathrm{CO})=0.5 \mathrm{kPa}$. Total gas flow rate: $1 \times 10^{-4} \mathrm{~mol} \mathrm{~s}^{-1}\left(150 \mathrm{~cm}^{3} \mathrm{~min}^{-1}\right)$. Error bars indicate the uncertainty in $\ln \mathrm{TOF} / \mathrm{Hz}$ values. Data points obtained from ref 11 over zirconia $\left(\mathrm{ZrO}_{2}\right)$ - and $\mathrm{Al}_{2} \mathrm{O}_{3}$-supported samples are also shown.

where heat transfer limitations are expected. Some of the kinetic data from our work lie in the same regime. For the YSZsupported sample $400 \mathrm{PtYSZ}$ it is clear that the activation energy decreases dramatically as the temperature increases (from $250 \pm 40$ to $9 \pm 1 \mathrm{~kJ} \mathrm{~mol}^{-1}$ ), indicating a transition to the light-off regime. The kinetic data below the $11 \mathrm{~K}$ limit for the $\mathrm{Al}_{2} \mathrm{O}_{3}$-supported samples $1 \mathrm{PtAl}_{2} \mathrm{O}_{3}$ and $400 \mathrm{PtAl}_{2} \mathrm{O}_{3}$ do not allow for reliable determination of activation energies. Apparent activation energies below the $11 \mathrm{~K}$ limit for the YSZ-supported samples 1PtYSZ, 4PtYSZ, 16PtYSZ, and 400PtYSZ are 135, 90, 95 , and $250 \mathrm{~kJ} \mathrm{~mol}^{-1}$, respectively (Figure S4 in the Supporting Information). (One must note that the statistical uncertainty associated with the determination of a gradient from only three or four data points is significant. This point is, however, largely overlooked in the literature.) The apparent activation energies for the YSZ-supported samples are in broad agreement with values reported in previous studies of unsupported $(35-137 \mathrm{~kJ}$ $\left.\mathrm{mol}^{-1}\right)^{23,25,29}$ and supported $\left(30-125 \mathrm{~kJ} \mathrm{~mol}^{-1}\right)^{26,27} \mathrm{Pt}$ catalysts (Table $S 1$ in the Supporting Information), with the exception of 400PtYSZ (three data points).

In order to ensure that there cannot be a significant difference between the sample temperature and the gas temperature, we limit the kinetic data employed in our analysis to rates of reaction below $4 \times 10^{-4} \mathrm{~mol} \mathrm{~s}^{-1} \mathrm{~m}^{-2}$ : i.e., where the maximum temperature difference between the sample and the gas phase is estimated to be not higher than $11 \mathrm{~K}$.

$\mathrm{CO}$ oxidation over Pt has been well studied with surface science techniques. At lower temperatures the Pt surface is almost entirely covered by strongly adsorbed CO. The rate of $\mathrm{CO}_{2}$ production is determined by the desorption rate of $\mathrm{CO}$, while oxygen can only adsorb at sites where carbon monoxide has desorbed, leading to first-order dependence on $\mathrm{O}_{2}$ partial pressure and negative-first-order dependence on $\mathrm{CO}$ partial pressure. At higher temperatures the Pt surface is covered by adsorbed oxygen. The rate of $\mathrm{CO}_{2}$ production is limited by the oxygen inhibition of carbon monoxide adsorption, leading to a first-order dependence in $\mathrm{CO}$ partial pressure and zero-order dependence in $\mathrm{O}_{2}{ }^{23-25}$ Numerous studies report TOF values for $\mathrm{Pt}$ on different supports near or at atmospheric pressure. 
For example, An et al. ${ }^{26}$ report TOF values from 0.01 to $2.2 \mathrm{~s}^{-1}$ for Pt nanoparticles supported on oxides $\left(\mathrm{NiO}, \mathrm{MnO}_{2}, \mathrm{Fe}_{2} \mathrm{O}_{3}\right.$, $\left.\mathrm{CeO}_{2}, \mathrm{SiO}_{2}\right)$ in a temperature range between 150 and $260{ }^{\circ} \mathrm{C}$ under reducing $\left(p\left(\mathrm{O}_{2}\right) / p(\mathrm{CO})=0.4\right)$ and oxidizing $\left(p\left(\mathrm{O}_{2}\right) /\right.$ $p(\mathrm{CO})=2.5)$ conditions at atmospheric pressure. Similar TOFs for $\mathrm{SiO}_{2}$-supported $\mathrm{Pt}$ were found by Cant and coworkers $^{28}$ near atmospheric pressure $\left(0.01-0.1 \mathrm{~s}^{-1}\right.$ in a temperature range of $\left.150-240{ }^{\circ} \mathrm{C}, p\left(\mathrm{O}_{2}\right) / p(\mathrm{CO})=0.5\right)$. McClure et al. ${ }^{29}$ studied the activity of $\mathrm{Pt} / \mathrm{SiO}_{2}$ at higher temperatures $\left(290-380{ }^{\circ} \mathrm{C}\right.$ ) and found TOFs in the range of $20-300 \mathrm{~s}^{-1}$ for $p\left(\mathrm{O}_{2}\right) / p(\mathrm{CO})$ between 0.5 and 2 at a lower total pressure $(1 \mathrm{kPa})$. Haneda et al. and Allian et al. ${ }^{22,30}$ reported TOFs between 0.3 and $2 \mathrm{~s}^{-1}$ for $\mathrm{Al}_{2} \mathrm{O}_{3}$-supported $\mathrm{Pt}$ in the temperature range of $120-160{ }^{\circ} \mathrm{C}$ at $p\left(\mathrm{O}_{2}\right) / p(\mathrm{CO})=2$ at atmospheric pressure.

TOF values have been also measured for both supported and unsupported $\mathrm{Pt}$ single crystals. Chen and co-workers ${ }^{31}$ reported TOFs of approximately $3 \mathrm{~s}^{-1}$ at $277^{\circ} \mathrm{C}\left(p\left(\mathrm{O}_{2}\right) / p(\mathrm{CO})=22.5\right)$ at a total pressure of $11 \mathrm{kPa}$ over a $\mathrm{Pt}(111)$ single crystal. McRea et al. ${ }^{32}$ reported TOF values of $20 \mathrm{~s}^{-1}$ at $350{ }^{\circ} \mathrm{C}$ for $\mathrm{CO}_{2}$ production over unsupported $\mathrm{Pt}(557)$ single crystals at a total pressure of $102 \mathrm{kPa}$ for $p\left(\mathrm{O}_{2}\right) / p(\mathrm{CO})=2.5$. Higher TOFs have also been obtained for supported Pt single crystals. Farkas et $\mathrm{al}^{33}$ studied the $\mathrm{CO}$ oxidation reaction over $\mathrm{Pt}(111)$ thin films supported on YSZ similar to the sample with $400 \mathrm{~m}$ (4.9 $\left.\times 10^{6} \mathrm{~m} / \mathrm{m}^{2}\right)$ tpb length used in our study. They reported a TOF value of $650 \mathrm{~s}^{-1}$ at $388{ }^{\circ} \mathrm{C}$ at $p\left(\mathrm{O}_{2}\right) / p(\mathrm{CO})=1.6$.

Clearly the activity of the Pt catalyst is complex and depends upon operating temperature, pressure, and microstructure of the catalyst; TOFs vary between $10^{-2}$ and $10^{2} \mathrm{~s}^{-1}$. The TOF values for our work are similar orders of magnitude (0.05-100 $\mathrm{s}^{-1}$ ) to those in the literature.

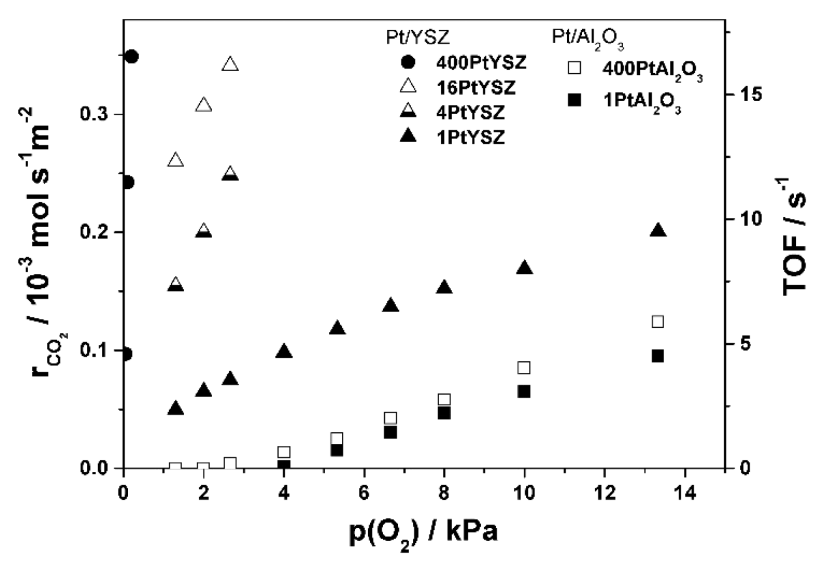

Figure 5. Influence of $p\left(\mathrm{O}_{2}\right)$ on the rate of $\mathrm{CO}_{2}$ production $\left(r_{\mathrm{CO}_{2}}\right)$ and the turnover frequency (TOF) over the four $\mathrm{Pt} / \mathrm{YSZ}$ samples and two $\mathrm{Pt} / \mathrm{Al}_{2} \mathrm{O}_{3}$ samples $\left(1 \mathrm{PtAl}_{2} \mathrm{O}_{3}\right.$ and $\left.400 \mathrm{PtAl}_{2} \mathrm{O}_{3}\right)$ at a constant $p(\mathrm{CO})=$ $0.5 \mathrm{kPa}$ at $288{ }^{\circ} \mathrm{C}$. Total gas flow rate: $1 \times 10^{-4} \mathrm{~mol} \mathrm{~s}^{-1}\left(150 \mathrm{~cm}^{3}\right.$ $\left.\min ^{-1}\right)$.

Figure 5 shows the dependence of the rate of $\mathrm{CO}_{2}$ production $\left(r_{\mathrm{CO}_{2}}\right)$ and TOF on $p\left(\mathrm{O}_{2}\right)$ at fixed $p(\mathrm{CO})$ over the four $\mathrm{Pt} / \mathrm{YSZ}$ samples and two $\mathrm{Pt} / \mathrm{Al}_{2} \mathrm{O}_{3}$ samples (samples $1 \mathrm{PtAl}_{2} \mathrm{O}_{3}$ and $400 \mathrm{PtAl}_{2} \mathrm{O}_{3}$ ) at $288{ }^{\circ} \mathrm{C}$. For all samples the rate of $\mathrm{CO}_{2}$ production increases with increasing $p\left(\mathrm{O}_{2}\right)$. It is clear for YSZ-supported samples that the smaller the structural length scale, the higher the rate for a given $p\left(\mathrm{O}_{2}\right)$. Note that the
$\mathrm{Al}_{2} \mathrm{O}_{3}$-supported samples exhibited much lower reaction rates in comparison to the YSZ-supported samples.

Additionally, experiments at different $p(\mathrm{CO})$ values were performed over the four $\mathrm{Pt} / \mathrm{YSZ}$ samples and two $\mathrm{Pt} / \mathrm{Al}_{2} \mathrm{O}_{3}$ samples (samples $1 \mathrm{PtAl}_{2} \mathrm{O}_{3}$ and $400 \mathrm{PtAl}_{2} \mathrm{O}_{3}$ ) (Figure 6). $p\left(\mathrm{O}_{2}\right.$ )

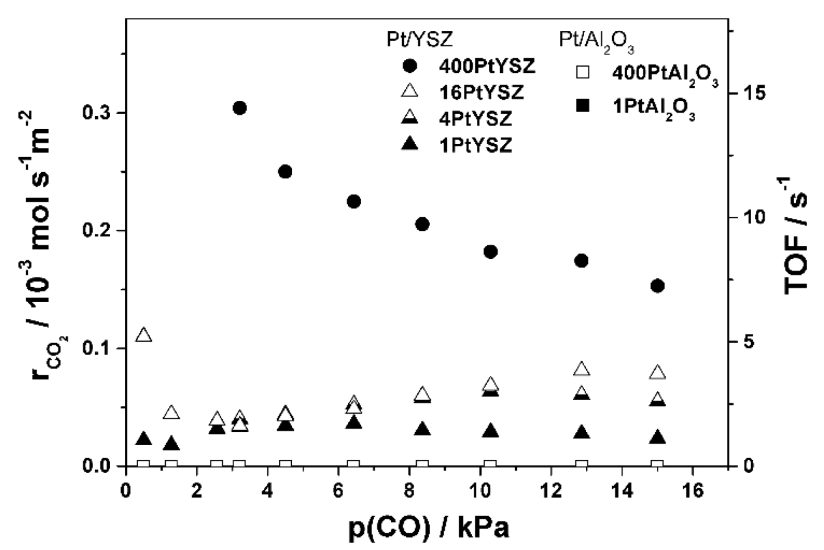

Figure 6. Influence of $p(\mathrm{CO})$ on the rate of $\mathrm{CO}_{2}$ production $\left(r_{\mathrm{CO}_{2}}\right)$ and the turnover frequency (TOF) over the four $\mathrm{Pt} / \mathrm{YSZ}$ samples and two $\mathrm{Pt} / \mathrm{Al}_{2} \mathrm{O}_{3}$ samples $\left(1 \mathrm{PtAl}_{2} \mathrm{O}_{3}\right.$ and $\left.400 \mathrm{PtAl}_{2} \mathrm{O}_{3}\right)$ at a constant $p\left(\mathrm{O}_{2}\right)=0.64 \mathrm{kPa}$ at $288^{\circ} \mathrm{C}$. Total gas flow rate: $1 \times 10^{-4} \mathrm{~mol} \mathrm{~s}^{-1}(150$ $\left.\mathrm{cm}^{3} \min ^{-1}\right)$.

was held constant, while $p(\mathrm{CO})$ was increased. It is well documented that strong adsorption of $\mathrm{CO}$ at this temperature will lead to $\mathrm{CO}$ poisoning and a reaction rate of $\mathrm{CO}_{2}$ production that will eventually decrease with increasing $p(\mathrm{CO}) .{ }^{34}$ Figure 6 shows that the rate appears to decrease from $p(\mathrm{CO})=0.5 \mathrm{kPa}$ to $p(\mathrm{CO})=1.0 \mathrm{kPa}$ for all YSZsupported samples. However, for all but the YSZ-supported sample 400PtYSZ, an increase in the reaction rate of $\mathrm{CO}_{2}$ production with increasing $p(\mathrm{CO})$ is eventually attained (at high $p(\mathrm{CO}))$. Thus, the YSZ-supported samples with a smaller Pt structural length scale showed higher reaction rates of $\mathrm{CO}_{2}$ production in comparison to the YSZ-supported samples with a larger Pt structural length scale. It is noteworthy that the rate of $\mathrm{CO}_{2}$ production for the $\mathrm{Al}_{2} \mathrm{O}_{3}$-supported samples is below the minimum measurable limit $\left(1 \times 10^{-10} \mathrm{~mol} \mathrm{~s}^{-1}\right)$.

Figure 7 shows the dependence of the rate of $\mathrm{CO}_{2}$ production $\left(r_{\mathrm{CO}_{2}}\right)$ versus $l(\mathrm{tpb})$ at 250,270 , and $290{ }^{\circ} \mathrm{C}$ for the patterned Pt/YSZ samples (samples 1PtYSZ, 4PtYSZ, and 16PtYSZ). The temperature range was selected to be between 250 and $290{ }^{\circ} \mathrm{C}$, because in this range kinetic data were obtained for the rates of $\mathrm{CO}_{2}$ production for the three YSZsupported patterned samples below the limit where the expected maximum temperature difference between the sample and the gas phase is $11 \mathrm{~K}$. The $\mathrm{Al}_{2} \mathrm{O}_{3}$-supported samples do not show any measurable activity in this temperature range. For the patterned YSZ-supported samples an increasing $l(\mathrm{tpb})$ (decreasing Pt length scale) appears to be correlated with higher rates of $\mathrm{CO}_{2}$ production. It is possible that the Pt active sites close to or at the tpb are modified due to the presence of the YSZ support. If we consider that only the Pt/YSZ interfacial sites are responsible for an increase in activity, then we would expect that the rates of $\mathrm{CO}_{2}$ production would increase linearly with increasing $l(\mathrm{tpb})$. This does appear to be broadly consistent with Figure 7. (We must also consider the possibility that there is an extended region of high activity close to the tpb as a result of contamination during fabrication. However, the 


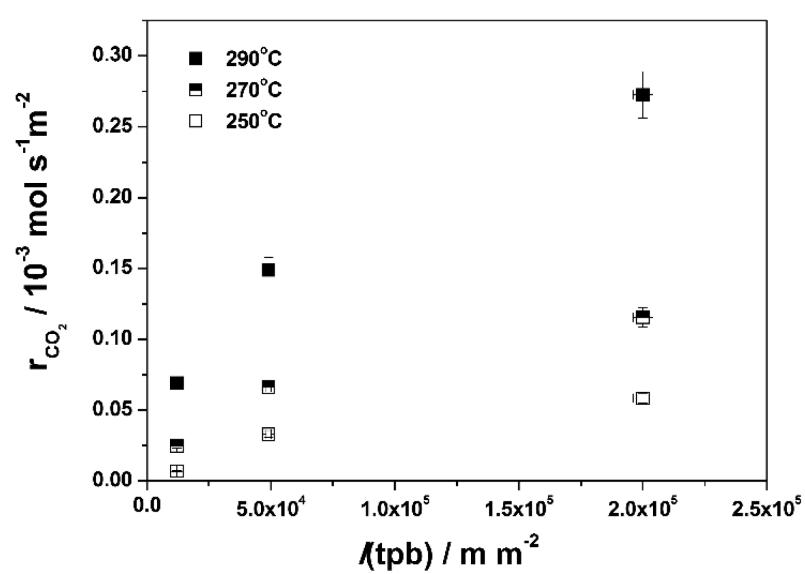

Figure 7. Dependence of the rate of $\mathrm{CO}_{2}$ production $\left(r_{\mathrm{CO}_{2}}\right)$ versus $l(\mathrm{tpb})$ at 250,270 , and $290{ }^{\circ} \mathrm{C}$ for the patterned $\mathrm{Pt} / \mathrm{YSZ}$ samples (1PtYSZ, 4PtYSZ, and 16PtYSZ). Total gas flow rate: $1 \times 10^{-4} \mathrm{~mol}$ $\mathrm{s}^{-1}\left(150 \mathrm{~cm}^{3} \mathrm{~min}^{-1}\right)$. Error bars indicate the uncertainty in $l(\mathrm{tpb})$ and $r_{\mathrm{CO}_{2}}$ values.

data presented here were obtained with two different methods of sample fabrication (the higher tpb involving dewetting and not ablation). We therefore suggest that contamination is not the primary cause of the behavior.)

However, during the reaction an oxygen chemical potential difference will exist between the support and the Pt catalyst as a natural consequence of the difference in $\mathrm{CO}$ oxidation activity of the YSZ or $\mathrm{Al}_{2} \mathrm{O}_{3}$ surface (low activity) and the Pt surface (high activity). The residual electronic conductivity of YSZ may facilitate the transfer of species from support to catalyst. Similar processes would not be expected to occur when $\mathrm{Pt}$ is supported on $\mathrm{Al}_{2} \mathrm{O}_{3}$. Such species would be able to access active sites some distance from the tpb through surface diffusion. If the structural length scale of the $\mathrm{Pt}$ films is much greater than the diffusional length scale of any diffusing intermediate species supplied from the support, we would expect any modification of coverage to be confined to a region close to the tpb; the diffusional length scale depends upon the ratio of the surface diffusion coefficient of the diffusing species to the equivalent first-order rate constant for consumption of the diffusing species through the reaction. Hence, we would expect a linear correlation between the rate of $\mathrm{CO}_{2}$ production and the increasing $l(\mathrm{tpb})$. (If the diffusional length scale is greater than the Pt length scales, then we would expect no correlation with the Pt length scales, as the Pt film should remain uniform and free of gradients in the coverage of any diffusing species.) Figure 8 shows the rate of $\mathrm{CO}_{2}$ production normalized by the length of the three-phase boundary $\left(r_{\mathrm{CO}_{2}}{ }^{\prime}\right)$ versus the areaspecific length of the three-phase boundary $(l(\mathrm{tpb}))$. The tpb length normalized rate of $\mathrm{CO}_{2}$ production appears to be a stronger function of the area-specific length of the three-phase boundary at higher temperatures. This might be expected if the diffusional length scale is of the same order of magnitude as the structural length scale of the $\mathrm{Pt}$ films at these higher temperatures. Such comparable length scales would mean that an increase in tpb length will now have a diminished impact on rate, as diffusional processes are already able to affect the whole of the structure. We tentatively suggest therefore, in broad agreement with ref 8 , that for the YSZ-supported samples the presence of the three-phase boundary facilitates an additional channel of oxygen supply to the Pt surface via a

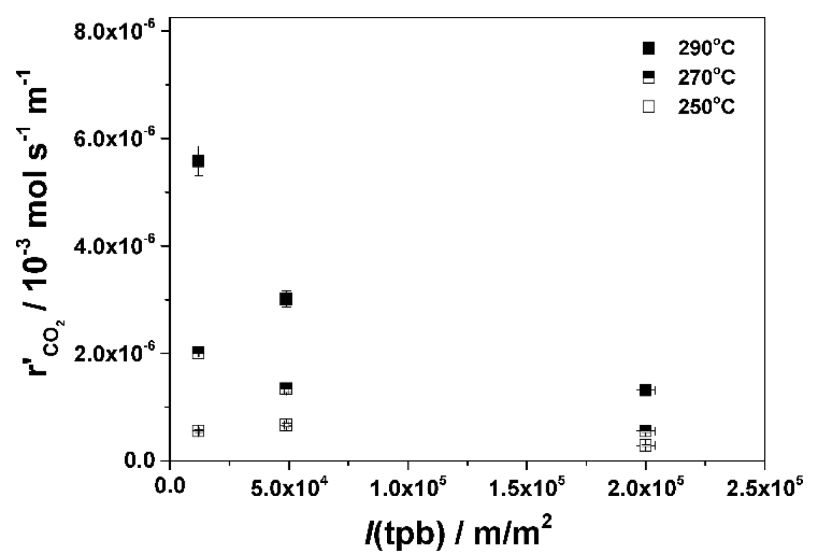

Figure 8. Dependence of the rate of $\mathrm{CO}_{2}$ production $\left(r_{\mathrm{CO}_{2}}\right)$ normalized by the length of the three-phase boundary $\left(r_{\mathrm{CO}_{2}}{ }^{\prime}\right)$ versus $l(\mathrm{tpb})$ at 250,270 , and $290{ }^{\circ} \mathrm{C}$ for the patterned $\mathrm{Pt} / \mathrm{YSZ}$ samples (1PtYSZ, 4PtYSZ, and 16PtYSZ). Total gas flow rate: $1 \times 10^{-4} \mathrm{~mol}$ $\mathrm{s}^{-1}\left(150 \mathrm{~cm}^{3} \mathrm{~min}^{-1}\right)$. Error bars indicate the uncertainty in $l(\mathrm{tpb})$ and $r_{\mathrm{CO}_{2}{ }^{\prime}}$ values.

diffusional process which has a diffusional length scale on the order of $10 \mu \mathrm{m}$ or less.

\section{CONCLUSION}

In this study the influence of the length and the nature of the three-phase boundary (tpb) on the kinetics of patterned $\mathrm{Pt}$ (111) single-crystal catalysts for $\mathrm{CO}$ oxidation was studied as a function of temperature and $p\left(\mathrm{O}_{2}\right)$ and $p(\mathrm{CO})$ at atmospheric pressure. A series of supported $\mathrm{Pt}$ catalysts (supported on single-crystal $\mathrm{YSZ}$ or $\mathrm{Al}_{2} \mathrm{O}_{3}$ support) were studied that exhibit area-specific lengths of the three-phase boundary that vary over 4 orders of magnitude from $4.5 \times 10^{2}$ to $6.9 \times 10^{6} \mathrm{~m} \mathrm{~m}^{-2}$, equivalent to structural length scales of $0.2 \mu \mathrm{m}$ to approximately $9000 \mu \mathrm{m}$. If $\mathrm{Pt}$ is supported on an oxygen ion conductor, then the rate of $\mathrm{CO}_{2}$ production has been shown to clearly depend on the area-specific length of the three-phase boundary $(l(\mathrm{tpb}))$. In particular, higher rates for $\mathrm{CO}_{2}$ production can be achieved for greater lengths of tpb $(l(\mathrm{tpb}))$ at lower temperatures and lower $p\left(\mathrm{O}_{2}\right)$. This finding is ascribed to the presence of the three-phase boundary, which facilitates an additional channel of oxygen supply to the $\mathrm{Pt}$ surface via a diffusional process. Quite in contrast, when $\mathrm{Pt}$ is supported on $\mathrm{Al}_{2} \mathrm{O}_{3}$ the rate of $\mathrm{CO}_{2}$ production is much lower than the rate of $\mathrm{CO}_{2}$ production over a $\mathrm{Pt} / \mathrm{YSZ}$ sample and does not depend strongly on $l(\mathrm{tpb})$.

\section{ASSOCIATED CONTENT}

\section{Supporting Information}

The Supporting Information is available free of charge on the ACS Publications website at DOI: 10.1021/acscatal.6b00829.

Material characterization via HRSEM, AFM, and XRD, an Arrhenius plot, and activation energies $\left(E_{\mathrm{a}}\right)$ reported in the literature for the $\mathrm{CO}$ oxidation over supported and unsupported Pt catalysts (PDF)

\section{AUTHOR INFORMATION}

\section{Corresponding Authors}

*E-mail for J.J.: Juergen.Janek@phys.Chemie.uni-giessen.de.

*E-mail for I.S.M.: i.metcalfe@ncl.ac.uk. 


\section{Author Contributions}

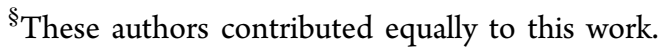

\section{Notes}

The authors declare no competing financial interest.

\section{ACKNOWLEDGMENTS}

The research leading to these results has received funding from the European Research Council under the European Union's Seventh Framework Programme (FP/2007-2013)/ERC Grant Agreement Number 320725 and from the EPSRC via Grants EP/G012865/1 and EP/G025649/1. This study has also been funded by the German Research Foundation (DFG) through project Ja648/17-1. Data supporting this publication is openly available under an "Open Data Commons Open Database License". Additional metadata are available at 10.17634/ 081371-1. Please contact Newcastle Research Data Service at rdm@ncl.ac.uk for access instructions.

\section{REFERENCES}

(1) (a) Dow, W. P.; Huang, T. J. J. Catal. 1994, 147, 322-332. (b) Metcalfe, I. S.; Sundaresan, S. AIChE J. 1988, 34, 195-208. (c) Somorjai, G. A.; Park, J. Y. Angew. Chem., Int. Ed. 2008, 47, 92129228.

(2) Schwab, G. M. Angew. Chem., Int. Ed. Engl. 1967, 6, 375-376.

(3) (a) Haruta, M. Catal. Surv. Jpn. 1997, 1, 61-73. (b) Haruta, M.; Yamada, N.; Kobayashi, T.; Lijima, S. J. Catal. 1989, 115, 301-309.

(c) Vaughan, O. Nat. Nanotechnol. 2010, 5, 5-7.

(4) Burch, R.; Flambard, A. R. J. Catal. 1982, 78, 389-405.

(5) For example, see: (a) Campbell, C. T. Nat. Chem. 2012, 4, 597-

598. (b) Conner, W. C.; Falconer, J. L. Chem. Rev. 1995, 95, 759-788.

(6) For example, see: Pacchioni, G. Phys. Chem. Chem. Phys. 2013, $15,1737-1757$.

(7) For example, see: Hayek, K.; Kramer, R.; Paal, Z. Appl. Catal., A 1997, 162, 1-15.

(8) For example, see: (a) Zhdanov, V. P.; Kasemo, B. J. Catal. 1997, 170, 377-389. (b) Barth, J. V. Surf. Sci. Rep. 2000, 40, 75-149.

(9) (a) Ertl, G.; Knözinger, H.; Weitkamp, J. Handbook of heterogeneous catalysis; VCH: Weinheim, Germany, 1997. (b) Somorjai, G. A.; Li, Y. M. Proc. Natl. Acad. Sci. U. S. A. 2011, 108, 917-924. (c) Johanek, V.; Laurin, M.; Grant, A. W.; Kasemo, B.; Henry, C. R.; Libuda, J. Science 2004, 304, 1639-1644.

(10) (a) Imbihl, R.; Behm, R. J.; Schlogl, R. Phys. Chem. Chem. Phys. 2007, 9, 3459-3459. (b) Freund, H. J. Top. Catal. 2008, 48, 137-144.

(11) Contreras, A. M.; Yan, X. M.; Kwon, S.; Bokor, J.; Somorjai, G. A. Catal. Lett. 2006, 111, 5-13.

(12) Johansson, S.; Osterlund, L.; Kasemo, B. J. Catal. 2001, 201, 275-285.

(13) Larrea, A.; Sola, D.; Laguna-Bercero, M. A.; Pena, J. I.; Merino, R. I.; Orera, V. M. J. Electrochem. Soc. 2011, 158, B1193-B1197.

(14) Bansal, N. P.; Singh, P.; Widjaja, S.; Singh, D. Advances in solid oxide fuel cells VII: a collection of papers presented at the 35th International Conference on Advanced Ceramics and Composites, January 23-28, 2011, Daytona Beach, Florida; Wiley: Hoboken, NJ, 2011; p xiii.

(15) Lin, W.; Herzing, A. A.; Kiely, C. J.; Wachs, I. E. J. Phys. Chem. C 2008, 112, 5942-5951.

(16) Chen, A. C.; Holt-Hindle, P. Chem. Rev. 2010, 110, 3767-3804.

(17) Beck, G.; Fischer, H.; Mutoro, E.; Srot, V.; Petrikowski, K.; Tchernychova, E.; Wuttig, M.; Ruhle, M.; Luerben, B.; Janek, J. Solid State Ionics 2007, 178, 327-337.

(18) Ryll, T.; Galinski, H.; Schlagenhauf, L.; Elser, P.; Rupp, J. L. M.; Bieberle-Hutter, A.; Gauckler, L. J. Adv. Funct. Mater. 2011, 21, 565572.

(19) (a) Popke, H.; Mutoro, E.; Luerssen, B.; Janek, J. Catal. Today 2013, 202, 12-19. (b) Baumann, N.; Mutoro, E.; Janek, J. Solid State Ionics 2010, 181, 7-15.
(20) Chakraborty, J.; Maity, T.; Kumar, K.; Mukherjee, S. Adv. Mater. Res. 2014, 996, 855-859.

(21) Bolz, R. E.; Tuve, G. L. CRC handbook of tables for applied engineering science, 2nd ed.; CRC Press: Boca Raton, FL, 1973; p 1166.

(22) Allian, A. D.; Takanabe, K.; Fujdala, K. L.; Hao, X.; Truex, T. J.; Cai, J.; Buda, C.; Neurock, M.; Iglesia, E. J. Am. Chem. Soc. 2011, 133, $4498-4517$.

(23) Berlowitz, P. J.; Peden, C. H. F.; Goodman, D. W. J. Phys. Chem. 1988, 92, 5213-5221.

(24) McClure, S. M.; Goodman, D. W. Chem. Phys. Lett. 2009, 469, $1-13$.

(25) Hardacre, C.; Ormerod, R. M.; Lambert, R. M. Chem. Phys. Lett. 1993, 206, 171-174.

(26) An, K.; Alayoglu, S.; Musselwhite, N.; Plamthottam, S.; Melaet, G.; Lindeman, A. E.; Somorjai, G. A. J. Am. Chem. Soc. 2013, 135, 16689-16696.

(27) Venderbosch, R. H.; Prins, W.; Swaaij, W. P. M. Chem. Eng. Sci. 1998, 53, 3355-3366.

(28) Cant, N. W.; Hicks, P. C.; Lennon, B. S. J. Catal. 1978, 54, 372383.

(29) McClure, S. M.; Lundwall, M.; Zhou, Z.; Yang, F.; Goodman, D. W. Catal. Lett. 2009, 133, 298-306.

(30) Haneda, M.; Watanabe, T.; Kamiuchi, N.; Ozawa, M. Appl. Catal., B 2013, 142-143, 8-14.

(31) Chen, M. S.; Cai, Z.; Yan, Z.; Gath, K. K.; Axnanda, S.; Goodman, D. W. Surf. Sci. 2007, 601, 5326-5331.

(32) McCRea, K. R.; Parker, J. S.; Somorjai, G. A. J. Phys. Chem. B 2002, 106, 10854-10863.

(33) Farkas, A.; Zalewska-Wierzbicka, K.; Bachmann, C.; Goritzka, J.; Langsdorf, D.; Balmes, J.; Janek, J.; Over, H. J. Phys. Chem. C 2013, 117, 9932-9942.

(34) Song, W. Y.; Jansen, A. P. J.; Degirmenci, V.; Ligthart, D. A. J. M.; Hensen, E. J. M. Chem. Commun. (Cambridge, U. K.) 2013, 49, 3851-3853. 